\title{
ANALYSIS OF THE FORMING PROCESS OF CONICAL-LIKE HELICAL SURFACES WITH ROLLER TOOLS
}

\author{
W. KACALAK, Z. BUDNIAK* and F. SZAFRANIEC \\ Faculty of Mechanical Engineering \\ Koszalin University of Technology \\ ul. Racławicka 15-17, 75-620 Koszalin, POLAND \\ E-mail: wojciech.kacalak@tu.koszalin.pl \\ zbigniew.budniak@tu.koszalin.pl \\ filip.szafraniec@tu.koszalin.pl
}

\begin{abstract}
The article presents a methodology of an analysis and modeling of technological systems and the grinding process of conical-like helical surfaces with the use of modern CAD/CAE systems and calculations in the Matlab system. The methodology developed allows one to carry out simulation tests for the accuracy of the grinding process of helical surfaces taking into consideration the deviations of the location and shape of the system's elements, axial and radial striking the spindle of the workpiece machined and the grinding wheel as well as the tool's geometrical features.
\end{abstract}

Key words: grinding, $\mathrm{CAD} / \mathrm{CAE}$, axial profile, helical surface, Matlab.

\section{Introduction}

Problems related to a grinding tool for helical surfaces have constituted the subject of many papers, of which the items (Kacalak et al. [1], Kacalak et al. [2], Kacalak [3]) can be mentioned in the context of this paper.

In many modern devices, very high positioning precision of measuring and machining systems is required. This especially concerns mechanisms for precision displacements, dividing mechanisms and other systems that support movement steadiness and good attenuation of vibrations during work in the conditions of changeable loads. In the applications mentioned above, screw and rolling gears as well worm gears are the most useful. Great jump precision and specified helical surface features are required from them.

For this reason, the use of the methods (Kacalak [3], Skoczylas [4], Wei et al. [5], Wei et al. [6], Marciniak [7]) that ensure minimization of jump deviations and of profile deviations is essential in the production of gears with high kinematic precision.

The geometrical imprecision of the MTWT (machine tool-tool holder-workpiece - tool) technological system, thermal and mechanical deformations of the workpiece ground and the machine tool are the main causes of the occurrence of systematic changes in the deviations of the jump of the workpiece machined. Axial striking of the workpiece spindle and of the lead-screw as well as imprecision of the kinematic chain of the machine tool (Kacalak et al. [1]) are the most important causes of local, random or harmonic changes in jump deviations. The thermal deformation of the workpiece machined (Kacalak [3]), the thermal and mechanical deformation of the lead-screw and axial striking of the lead-screw and the workpiece spindle exert the greatest influence on jump deviation. The deviations of the screw surface profile are caused by the geometrical imprecision of the MTWT technological system, the kinematic imprecision of

\footnotetext{
* To whom correspondence should be addressed
} 
the grinder, elastic deformations of the technological system, the deviations of the location and the deviations of the shape of the tool.

The helical surface of the worm is the envelope of the active surface of the grinding wheel that displaces in relation to it with helical motion; for this reason, it is its shape and change during machining that the manufacturing accuracy of the gear and its operating properties depend on.

A change to the curvature radius of the surface profile has a significant influence on the condition of the gear coupling. If we obtain a curvature radius that is smaller than the nominal one, this contributes to an unfavorable local increase of pressures in the gear coupling area, which results in a reduction of the load capacity and durability of the gear, and it leads to fast deterioration of its precision. It is therefore essential for the profile curvature not to be smaller than the nominal one, and at the same time it needs to fit in the outline tolerance field.

In the case of foreseen modifications to the interaction models of the surface of the tool and of the workpiece in the Matlab system and the helical surface profile, it should be preceded by an analysis of stereometric features and operating effects; moreover, the influence needs to be taken into account of unavoidable profile deviations caused by the location deviations and the shape wear of the grinding wheel. For this purpose, a methodology was developed of modeling and analyzes of grinding of the helical surfaces of the worms with the use of CAD/CAE computer and mathematical techniques.

\section{Methodology of modeling and analysis}

In order to carry out an analysis of the grinding precision of the helical surface of the worm, the methodology presented in Fig. 1 was developed. The method presented herein uses modern computational systems based on advanced CAD/CAE engineering software (Budniak [8]).

The basic elements of the method presented are as follows:

- modeling of spatial dimensional chains,

- parametric modeling of parts and assembly of the OUPN technological system for helical surface grinding including the spatial dimensional chain,

- building of a kinematic model,

- simulation tests of grinding of the helical worm surface,

- analysis of the results of simulation tests: precision of the jump and axial profile of the worm, etc.

The virtual MTWT technological system was created based on the constructive geometry of the CAD system in accordance with the spatial dimensional chain developed. Building such a system allows one to carry out simulation tests to determine the geometrical parameters of the helical surface ground including the coordinates of axial and free other profiles for the surfaces being the envelope of the locations of tools with conical-like, torus-like and with any (permissible) profiles. Carrying out analyses of the influence of the deviations of the relative location of tools and the helical surface ground on the geometrical features of the surface machined is possible.

The virtual model built of the technological system also allows one to perform any transformations and geometrical visualizations. Due to the high requirements for the load capacity, reliability and durability of the worm gears, analyses need to be performed at the designing stage to determine the basic quality indexes of the gear, i.e., that the physical movement charts and collaboration track charts need to be performed. 


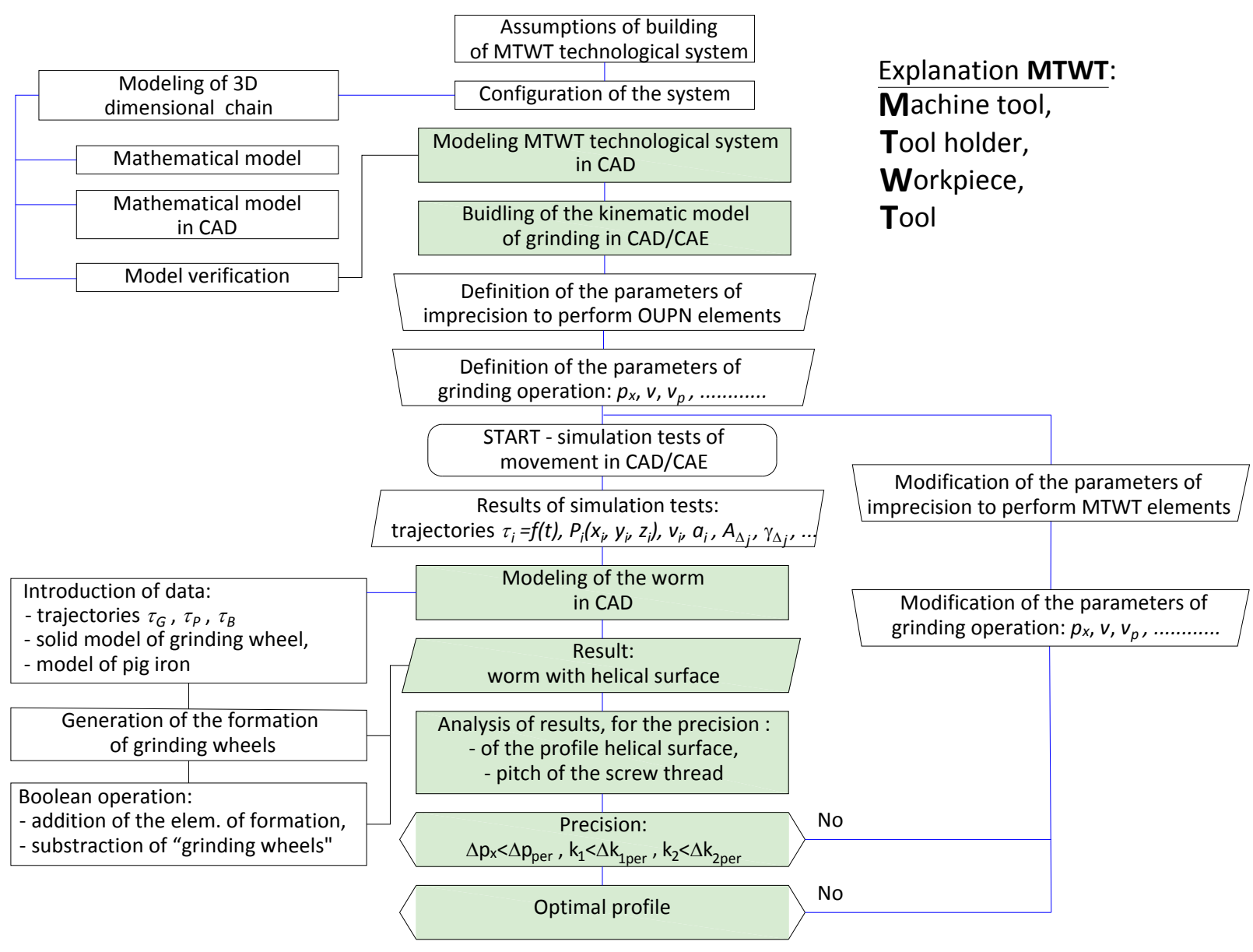

Fig.1. Flowchart of computer aided system and analyses of technical systems.

The methods to model the machining process of gears with the use of the mathematical model (Marciniec et al. [9], Marciniec et al. [10], Kacalak et al. [11], Skoczylas [12]) and the solid model (Marciniec et al. [13], Marciniec et al. [14], Rakowiecki et al. [15], Wronkowicz et al. [16], Skawiński et al. [17], Twardoch [18]) are known.

The first one projects the geometry and kinematics of the process with the use of mathematical dependences (the vector and matrix method), i.e., with the use of the mathematical model, whose results, depending on the complexity of the method, may take the form of the equations of active teeth surfaces in simpler analytical cases (Marciniec et al. [9] 2002), or in the case of more compound machining methods, a discrete form determined by the grids of points that correspond to a given grid of reference.

In the paper (Kacalak et al. [11]), the authors developed a computational model in the Matlab software introducing the mathematical dependences of deviations from grinding parameters and from measurable factors that are non-controllable and are connected with the geometrical and kinematic precision of the machine tool and its static and dynamic characteristics. The application developed also allows one to determine the working length of the knife-edge in grinding helical surfaces as well as the shape of the grinding sphere and the coil profile. A visualization of the grinding spheres of helical surface with a rectilinear axial profile before grinding with a roller grinding wheel with a trapezoidal profile is presented in Fig.2. 
The other method (with the use of a solid model) consists in a simulation of machining in a CAD environment and it consists in the determination of the trajectories of machining traces and a successive performance of the logical operations of subtraction between the solids of the workpiece machined and the tool.
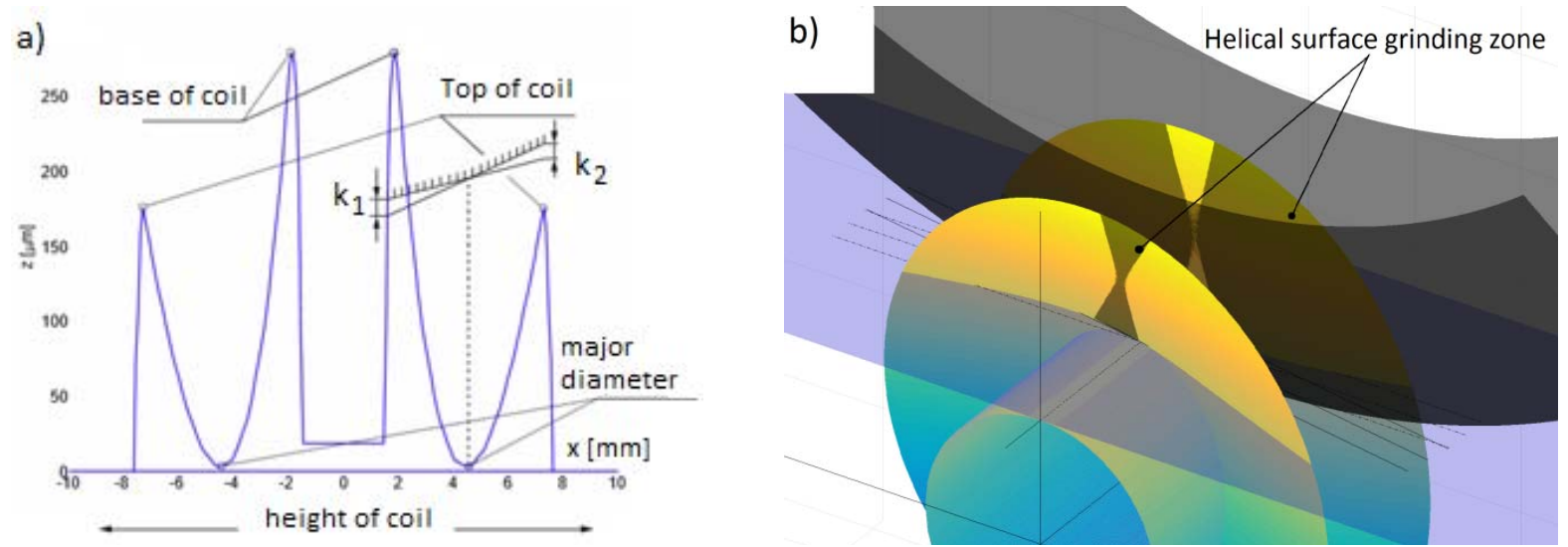

Fig.2. Simulation results of the study of the grinding spheres of helical surface with rectilinear axial profile before grinding with roller grinding, in the Matlab software, a) of the allowance for variations in thickness along the height contour grinding surface, $b$ ) visualization of the grinding spheres

In the article, the results (in a discrete form) will be presented of the use of the mathematical model of the machining of the helical surface of the worm in a worm gear and of the simulation of machining on a solid model. These methods reflect the course of the real process owing to the representation of its geometry and kinematics in the CAD environment. The models that are produced enable a verification of the results obtained on the grounds of a mathematical model. They also allow one to assess the selected settings of the machine tool as regards obtaining the surface profile precision of the helical surface of the worm.

\section{Modeling of the technological system}

The need of a geometrical analysis of the features of the technological system results from the fact that the profiles of some helical surfaces do not depend on their parameters only but also on the shape, dimensions and locations of the tool. The determination of these dependences and their analysis is essential for the proper selection of the profile, the dimensions and the location of the tool to enable one to obtain a specific shape of the helical surface. Such an analysis may constitute the basis of the control of the modification introduced to the helical surface profile consisting in replacing the nominal surface with a helical surface of a different type or with a helical surface of the same type yet with a different profile. Such an analysis is also needed for an assessment of the influence of the diameter of the roller tool on the profile of the surface machined.

The mathematical model of the machining system consists of a set of local coordinates systems presented in Fig.3, which expresses the mutual geometrical and kinematical connections between the basic units of the machine tool starting from the base (cradle) $b$, the grinder table $t$, the headstock of the workpiece machined $h$, the spindle of the workpiece machined $s$, the sleigh of the tool headstock $c$, the grinding wheel headstock $d$, the grinding wheel spindle $w$, the grinding wheel $g$, the tailstock $k$, the tailstock axle $o$ up to the workpiece machined $p$. These connections are expressed with the use of the matrix of transformation $M_{t}$ and the matrix of rotation $M_{r}$.

The absolute system of coordinates $O x y z$ is a fixed (base) system connected with the body of the machining tool. The remaining systems are local moving systems of reference, which are stiffly connected with the elements of the technological system including the tool and the worm ground. The local systems of 
coordinates determine the change of their location during machining. The roller grinding wheel $g$ performs a rotational movement with speed $n_{s}$
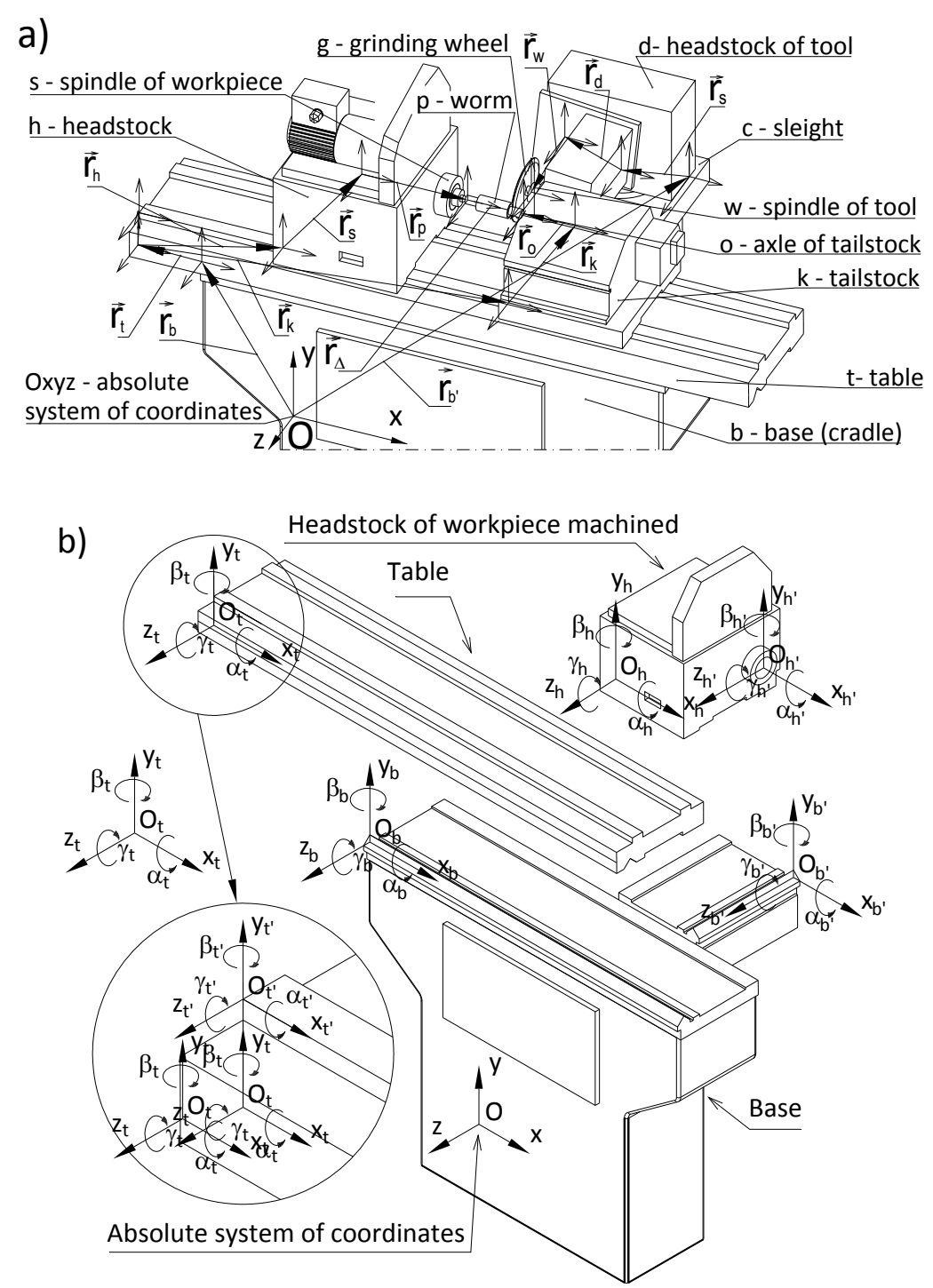

Fig.3. MTWT technological system where: a) machining system, b) selected elements of machining system - base $b$, grinder table $t$ and headstock of workpiece machined $h$.

The relocations of the members of the OUPN kinematic technological system during work constitute the idea of the OUPN kinematic technological system. A kinematic analysis of this system permits to answer the question as to what locations are accepted by the members of the system including tools (of the roller grinding wheel) in each moment in relation to the workpiece machined.

\section{Helical surface of the worm}

The helical surface of the worm machined with a roller tool is the envelope of the active surfaces of the tool that moves with a helical motion, which is concentric with the helical surface axis. This surface in a general case is not rectilinear. For an explicit determination of the helical surface which is machined with a roller tool, the following is to be given: the nominal profile and the dimensions of the grinding wheel and its 
location in relation to the helical surface. To determine a general equation of a helical surface which is machined with a roller tool, the following can be used: the envelope theory, the division method of the roller tool into an infinite number of elementary tools with infinitely small width (Kacalak [3]) or the method used to determine the family of the contact lines of the helical surface and the tool.

The absolute system of coordinates $O x y z$ and the local systems of coordinates connected with the members of the MTWT technological system shown in Fig.4a were introduced to the deliberations.

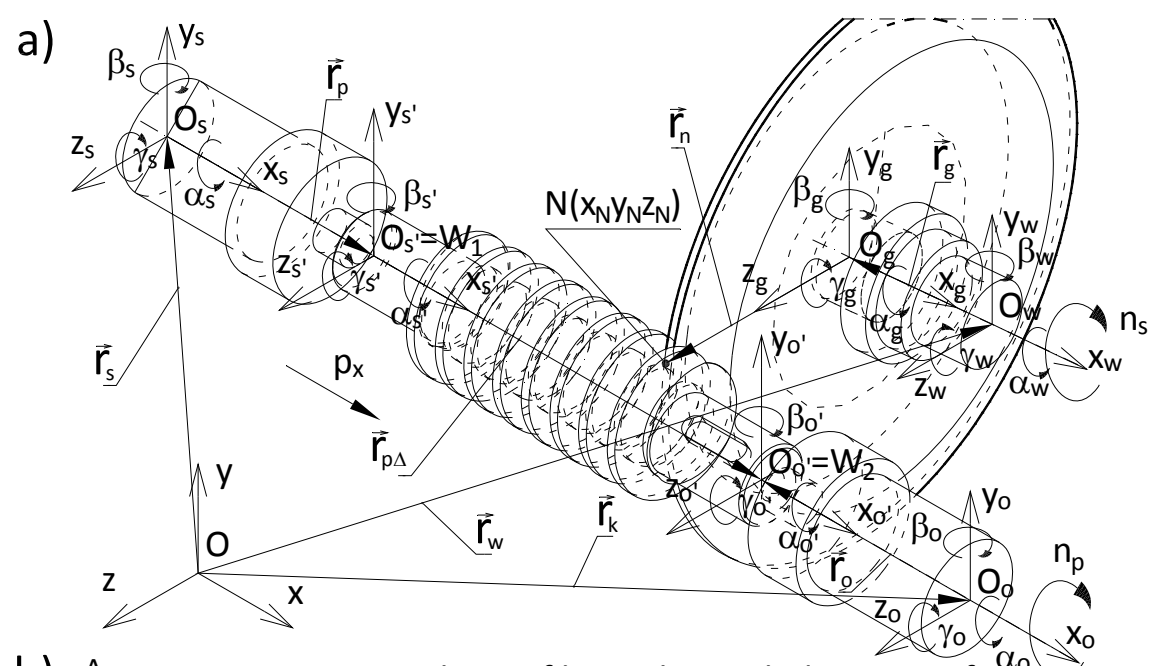

b) A Tangent to the profile on the pitch diameter of the worm

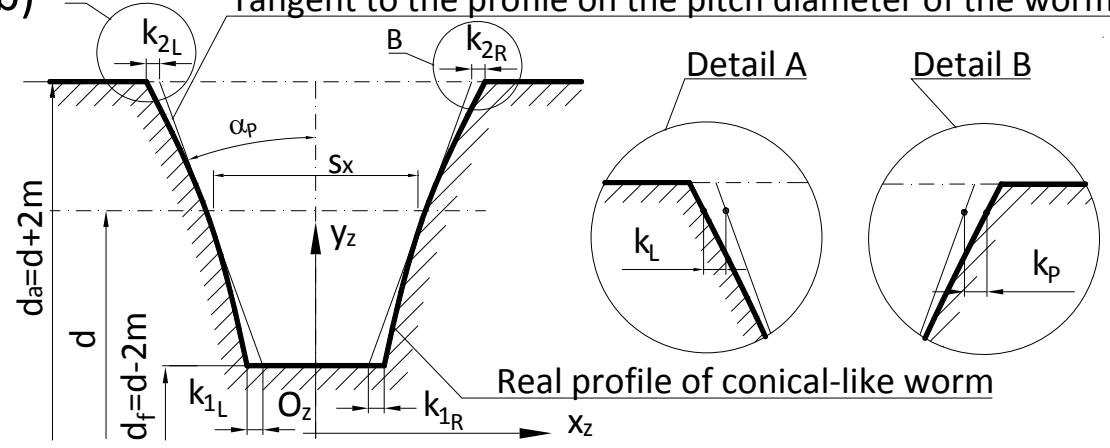

Fig.4. Formation of the conical-like helical surface of the worm, a) kinematic system, b) axial profile.

When the grinding wheel has a rectilinear axial profile, the system of its formation is exceptionally simple. As a result of grinding with such a grinding wheel, a conical-like helical surface is obtained. The axial profile of such a surface is convex. The methodology developed with the use of the CAD/CAE techniques allows one to determine the coordinates of the axial profile and its deviation from rectilinearity. It can be found as to what degree the values of these deviations depend on the parameters of the helical surface, the diameter and the nominal location of the tool and to determine the impact of the deviations of the tool profile and the deviations of its location.

The issue of the determination of the axial profile and an analysis of the deviations from the rectilinearity of the conical-like helical surface of the worm has been extensively presented in many studies (Kacalak et al. [1], Kacalak [3], Skoczylas [4], Marciniak [7]). The deviations were determined in relation to the straight line that is tangent to the axial profile at a point on the pitch diameter (Fig. $4 \mathrm{~b}$ ). The formulas were determined which define deviations $k_{1}$ and $k_{2}$ for the case when the tilt angle of the axle of the tool $\gamma_{\mathrm{N}}$ is equal to the tilt angle of the helical line on the reference cylinder.

For a more complete determination of the imprecision of the axial profile, deviations (parameters) $k_{L}$ and $k_{P}$ may be important, whose values change depending on the location of the profile point in the local 
system of coordinates $O_{z} x_{z} y_{z}$, whose beginning is on the symmetry axle of the worm. Deviations $k_{L}$ and $k_{P}$, which occur at the base of the worm, are marked as $k_{l_{L}}$ and $k_{l_{P}}$ while on the surface of its tops this is $k_{2_{L}}$ and $k_{2_{P}}$ (Fig.5).

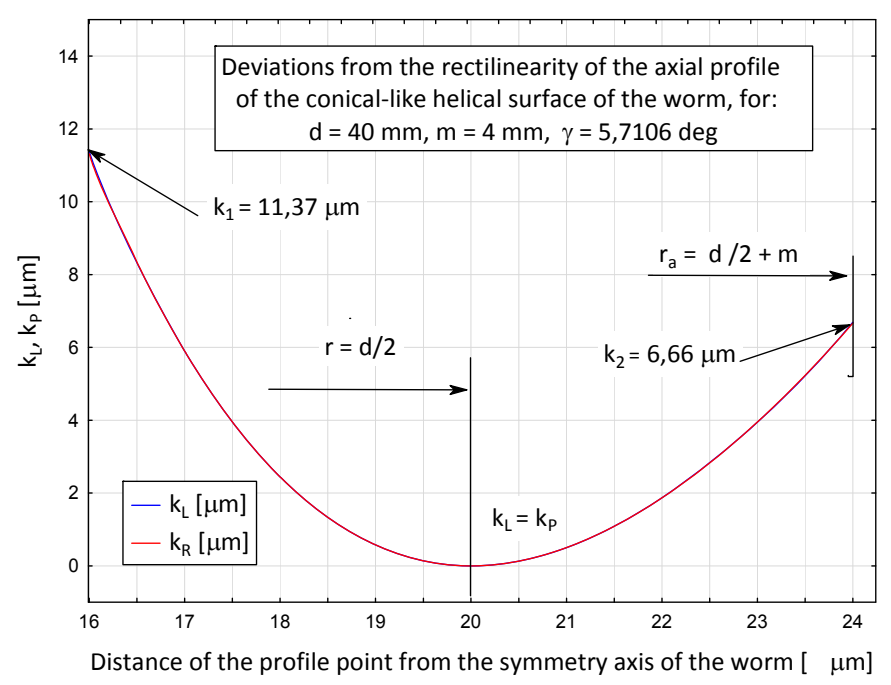

Fig.5. Deviations from the rectilinearity of the axial profile of the conical-like helical surface of singlethread worm.

The values presented of deviations from the rectilinearity do not take into account geometrical and kinematic imprecision or elastic deflections of the MTWT technological system, or the imprecision of the settings. It can be accepted that the axial profile of the worm was obtained for an ideal technological system, and so it may constitute a reference to a comparative analysis.

\section{Results of simulation tests}

The coordinates of the helical surface in the local system of coordinates of the worm $O_{z} x_{z} y_{z}$ can be determined using the kinematic model in the system of CAD - Solid Works. Knowing the values of the profile coordinates, the values of deviations $k_{L}$ and $k_{P}$ as well as $k_{l}$ and $k_{2}$ can be calculated.

To determine the axial profile of the conical-like helical surface of the worm taking into account the influence of the selected parameters of the geometrical and kinematic precision of the machining tool, deviations of the tool profile etc., numerical applications were developed. The charts in Fig.6 are presented as an illustration of the scope of deviations from the profile rectilinearity of the conical-like worm.

An analysis of the results of calculations points to the fact that a deviation of the axial profile (Fig.6a) has a great impact on the deviations from the rectilinearity of the axial profile of the helical surface of the worm (Fig.6b). This may result from the deviation of the grinding wheel after dressing, which is caused by the technological imprecision of the dressing device and an imprecision of its setting, by a deviation of the substitute profile (when it is accepted). The deviation of the grinding wheel profile can also be caused by a change of its shape as a result of wear and tear.

A deviation of the tilt angle of the grinding wheel axle in relation to the workpiece axle $\Delta \varphi=\left(\gamma_{N}-\gamma\right)$ has a significant influence on the value of the deviation of the profile from rectilinearity. For an explicit determination of this influence, it was accepted that deviations were always to be determined from the tangent to the profile on the pitch diameter. Deviations from the rectilinearity for the tangent to the profile on the diameter, for whom there is a conformity of the helical line tilt angle and the axis of the tilt 
angle of tool occurs, can also be determined. For the given parameters of calculations (Fig.6c), deviations from the rectilinearity of the left and right profile become asymmetrical. Deviation $k_{l}$ for the left profile occurring at the bases of the tooth of the worm is greater than deviation $k_{2}$. For the right profile, on its external surface, deviation from rectilinearity $k_{2}$ is greater than deviation $k_{1}$. In typical machining processes, the tilt angle of the axis of the grinding wheel $\gamma_{N}$ is, apart from exceptional cases, equal to the tilt angle of the helical line $\gamma$ on the reference cylinder. The deviation of angle $\gamma_{N}$ results from the deviation of the setting of this angle and from the deviation of the location of the grinding wheel axis in relation to the helical surface axis. This last deviation is caused by a geometrical imprecision of the MTWT technological system and by the deformations of the machine tool and the workpiece.

a)

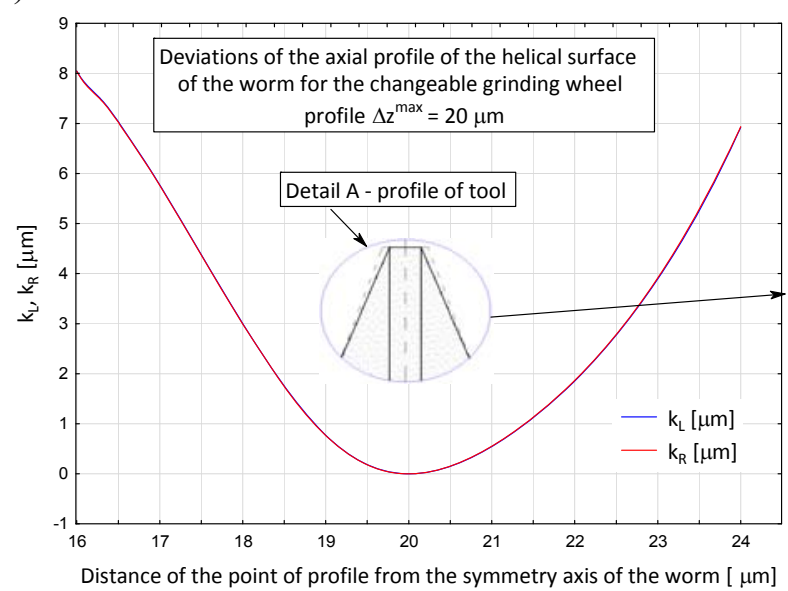

b)

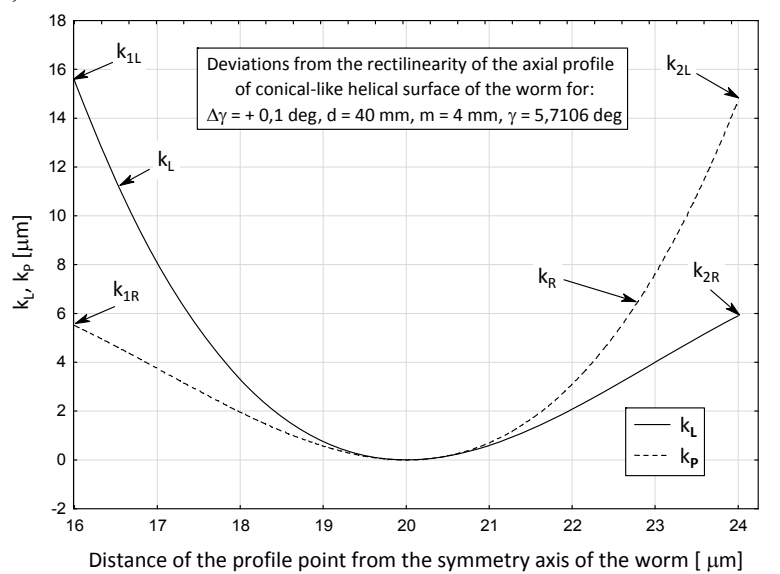

\section{Detail A}

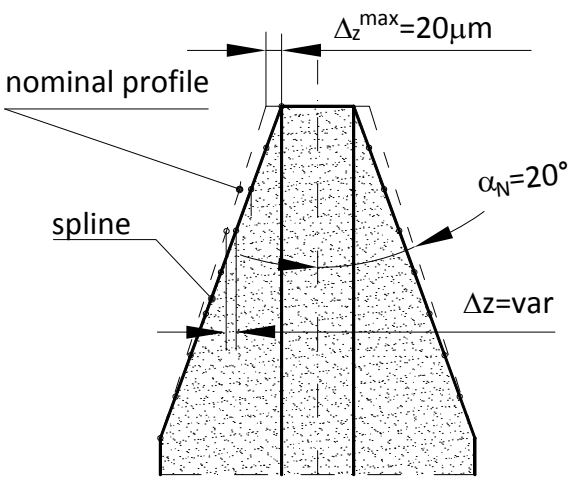

c)

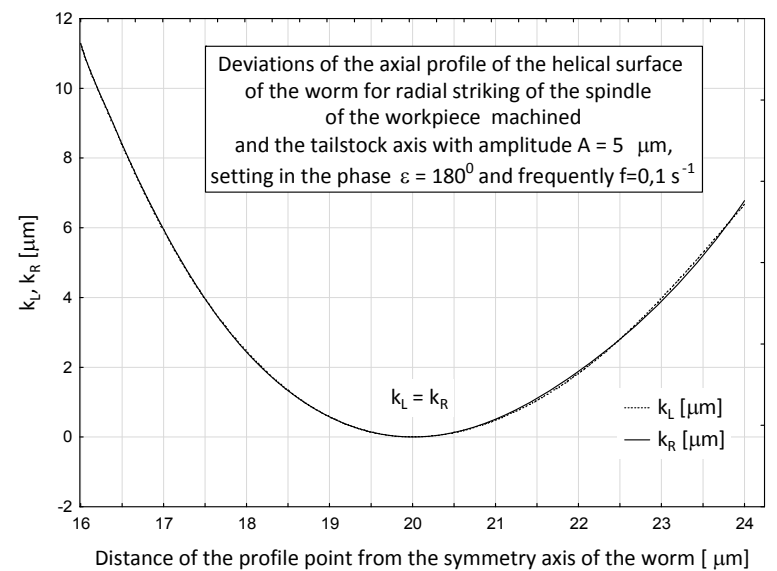

Fig.6. Deviations from the rectilinearity of the axial profile of the conical-like helical surface of a singlethread worm taking the following into account: a) deviations of the grinding wheel profile, b) deviations of the axis angle of the grinding wheel in relation to the axis of the workpiece $\Delta \varphi=\gamma_{N}-\gamma$, c) radial striking of the spindle of the workpiece machined and the tailstock axis.

It is evident based on the analyses carried out that deviations from the rectilinearity of the worm profile, which are caused by the radial striking of the workpiece spindle and the tailstock axis (Fig.6c), are negligible. It was accepted for the simulation tests that the amplitudes of radial striking of the spindle of the workpiece machined and the tailstock axis are identical, and they are $A=5 \mu \mathrm{m}$, and they have a phase shift in relation to each other $\varepsilon=180 \mathrm{deg}$, while the angular frequency of the workpiece machined is $\omega=1 \mathrm{~s}^{-1}$. 


\section{Conclusions}

In this article, the possibilities were presented of the current CAD/CAE systems to model and analyze MTWT technological systems. The simulation model developed, on the grounds of the methodology prepared, enables one to carry out the numerical analyses of the MTWT technological system of grinding of the conical-like helical surface of the worm based on a spatial dimensional chain. This allows the following among others:

- modeling of the helical surface of the worm and modular threads taking into consideration the impact of the geometrical and kinematic imprecision of the machine tool (axial and radial striking of the workpiece spindle, radial and axial striking of the grinding wheel spindle, imprecision of the performance of the elements of the OUPN technological system, kinematic imprecision of the feed screw - spindle system etc.), imprecision of the grinding wheel profile after dressing and imprecision of the settings of the machine tool;

- an analysis of the deviations of the axial profile of the conical-like helical surface of the worm.

The simulation model of the MTWT technological system of grinding of the conical-like helical surface of the worm with the roller grinding wheel with the use of CAD/CAE computer techniques takes into account numerous real machining parameters. The benefits resulting from the submitted analytical model can be great as they allow one to make a very thorough assessment of grinding of helical surfaces with roller grinding wheels as early as at the designing stage of the MTWT technological system to obtain the smallest possible values of the deviations of the geometrical and kinematic precision of the machine tool for the value of the deviations of the dimensional and shape precision of the workpiece.

Furthermore, the model developed to carry out a numerical analysis allows one to perform a simulation of machining with grinding wheels with other shapes and profiles.

\section{References}

[1] Kacalak W., Majewski M. and Budniak Z. (2015): Worm gear drives with adjustable backlash. - Journal of Mechanisms and Robotics-Transactions of the ASME, vol.8, pp.014504-1 -014504-7.

[2] Kacalak W., Majewski M. and Budniak Z. (2014): Worm gears with adjustable side clearance. - Mechanic, No.7, pp.526-533 (in Polish).

[3] Kacalak W. (1995): Selected Problems of Precise Worm Gear Drives Construction and Technology. - Mech. Eng. Depart. Koszalin, Monograph No.51, (in Polish).

[4] Skoczylas L. (2010): Synthesis of Mesh Geometry in Cylindrical Worm Gears with Worm of Arbitrary Profile. Publishing House of Rzeszow University of Technology, (in Polish).

[5] Wei J. and Zhang G. (2010): A precision grinding method for screw rotors using CBN grinding wheel. International Journal of Advanced Manufacturing Technology - Springer, No.48, pp.495-503.

[6] Wei J., Zhang Q., Xu Z. and Lyu P. (2010): Study on precision grinding of screw rotors using cbn wheel. International Journal of Precision Engineering and Manufacturing - Springer, vol.11, No.5, pp.651-658.

[7] Marciniak T. (2002): Characteristic wear as the basis for defining the abrasive wear rate in worm gear driver. Advances in Manufacturing Science and Technology, vol.2, No.2, pp.63-75.

[8] Budniak Z. (2015): Modelling and numerical analysis of assembly system. - Acta Mechanica et Automatica, vol.9, No.3, pp.145-150.

[9] Marciniec A. (2002): Synthesis and analysis of meshing for spiral bevel gears. - Publishing House of Rzeszow University of Technology, (in Polish).

[10] Marciniec A., Pisula J., Płocica M. and Sobolewski B. (2011): Design work on bevel gear transmissions applying the method of mathematical modeling and simulation in CAD environment. - Mechanic, No.7, pp.602-605 (in Polish). 
[11] Kacalak W. and Szafraniec F. (2015): Analysis of the shape and position of machining zone in the process of grinding the surface of the conical helical worm. - Mechanic, No.8-9, pp.159-163 (in Polish).

[12] Skoczylas L. (2010): Process automation of modelling of worm-gear wheels teeth. - Assembly and Automation Technology, No.1, pp.25-27 (in Polish).

[13] Marciniec A. and Sobolewski B. (2013): Method of spiral bevel gear tooth contact analysis performed in CAD environment. - Aircraft Engineering and Aerospace Technology, vol.85, No.6, pp.467-474.

[14] Marciniec A. and Sobolewski B. (2012): Application of the Autodesk Inventor software for simulation of the Gleason bevel gears mating. - Mechanic, No.1, pp.76-77 (in Polish).

[15] Rakowiecki T., Skawiński P.P. and Siemiński P. (2011): Using parametric templates of 3D CAD system for generating models of teeth of spiral semi-bevel gear. - Mechanic, No.12, pp.977-979 (in Polish).

[16] Woronkowicz A. and Wachla D. (2014): A generative cad model of a worm gear meshing. - Scientific Journal of Silesian University of Technology, Series Transport, vol.82, pp.291-300 (in Polish).

[17] Skawiński P., Siemiński P. and Pomianowski R. (2011): A method to generate solid body models of the bevel gear teeth by means of the simulation software in the 3D CAD system. - Mechanic, No.11, pp.922-924 (in Polish).

[18] Twardoch K. (2014): Digital geometric modelling of teeth profile by using CAD methodology. - Scientific Journal of Silesian University of Technology, Series Transport, vol.82, pp.271-279 (in Polish).

Received: October 21, 2016

Revised: December 9, 2016 